\title{
EGFR NP_005219.2:p.T790M
}

National Cancer Institute

\section{Source}

National Cancer Institute. EGFR NP 005219.2:p.T790M. NCI Thesaurus. Code C98503.

A change in the amino acid residue at position 790 in the epidermal growth factor receptor protein where threonine has been replaced by methionine. 